\title{
Effect of Different Acidic Agents on Surface Roughness of Feldspathic Porcelain
}

\author{
Zeynep Yesil Duymus1, Alper Ozdogan2*, Hamza Ulu² \\ ${ }^{1}$ Department of Prosthodontics, Faculty of Dentistry, Recep Tayyip Erdoğan University, Rize, Turkey \\ ${ }^{2}$ Department of Prosthodontics, Faculty of Dentistry, Atatürk University, Erzurum, Turkey \\ Email: *alprozdgn@gmail.com
}

Received 13 February 2016; accepted 27 March 2016; published 30 March 2016

Copyright (C) 2016 by authors and Scientific Research Publishing Inc.

This work is licensed under the Creative Commons Attribution International License (CC BY). http://creativecommons.org/licenses/by/4.0/

(c) (7) Open Access

\begin{abstract}
Objectives: The aim of this study was to evaluate the effect of different acidic agents on surface roughness of feldspathic porcelain. Materials and Methods: In this study, totally 60 disc shaped Noritake and Ceramco 3 feldspathic porcelain were used. The samples were divided into five groups and immersed in five acidic agents (coke, orange juice, lemonade, mineral water and black-carrot juice). After 168 hours, the specimens were evaluated surface roughness with profilometer. Results: The results showed that the highest surface roughness value $(4.46 \pm 2.9 \mu \mathrm{m})$ was identified in lemonade at Noritake porcelain and the lowest surface roughness value $(1.06 \pm 0.56$ $\mu \mathrm{m})$ was identified in mineral water at Ceramco 3 porcelain. The result of two-way analysis of variance test showed that there were no statistically significant differences between acidic agents on surface roughness of feldspathic porcelain $(p>0.05)$. Conclusions: The obtained data presented that the acidic drinks affected the surface roughness of feldspathic porcelain.
\end{abstract}

\section{Keywords}

Feldspathic Porcelain, Surface Roughness, Acidic Agents

\section{Introduction}

Dental porcelains have esthetic properties, biocompatibility and wear resistance, so they are being used in dentistry [1]. However, porcelain fragile structure is decreased the using for many years. The fracture of on the porcelain surface and the degradation of surface finish, as opposed to the attrition on the teeth as well as increased accumulation of plaque causes. Rough porcelain surfaces significantly reduce the strength of ceramic restorations and make them prone to fracture [2] [3].

*Corresponding author.

How to cite this paper: Duymus, Z.Y., Ozdogan, A. and Ulu, H. (2016) Effect of Different Acidic Agents on Surface Roughness of Feldspathic Porcelain. Open Journal of Stomatology, 6, 90-95. http://dx.doi.org/10.4236/ojst.2016.63011 
Metal ceramic restorations are usually used in fixed prosthodontic. Feldspathic porcelains are usually used as a veneering material for metal ceramic restorations and provide excellent esthetics and compressive strength [4]. The mixture of potassium feldspar and glass is being in the feldspathic porcelains. After incongruent melting, feldspathic porcelains contain 19 weight percentage (wt\%) of leucite crystals $\left(\mathrm{K}_{2} \mathrm{O} \cdot \mathrm{Al}_{2} \mathrm{O}_{3} \cdot 4 \mathrm{SiO}_{2}\right)[5]$.

The composition, microstructure, chemical properties of the ceramic materials, erosive or acidic agents, may influence the durability of dental ceramics [6]. In daily life, we often use acidic agents in foods which are available. However, the consumption of acidic drinks that contain acid ratio is greater and heavily consumed by every segment of society. These acidic agents lead to attrition tooth and restorations because of their chemical structures. As a result, the accumulation of plaque and fractures occur in the restoration, so the restoration of the life is shortened.

The aim of this study was to evaluate the effect of different acidic agents on surface roughness of feldspathic porcelain. The hypothesis of this study was that the acidic agents would increase the roughness of feldspathic porcelain and depending on the type, acidic agents would be made of roughening differently.

\section{Materials and Methods}

In this study, totally 60 disc shaped specimens which were $2 \mathrm{~mm}$ thickness and $10 \mathrm{~mm}$ diameter of two different feldspathic porcelains Ceramco 3 (Dentsply, Burlington, New Jersey, USA), Noritake (Noritake Dental Supply Co. Ltd., Nagoya, Japan) were prepared.

Firstly, the wax models likeness specimens were prepared for the preparing porcelain specimens. Then, the wax models were immersed in elastomeric impression material. The wax models took out, after the impression material had hardened and the impression molds have been prepared for using porcelain specimens. After the isolation, the dentin and enamel porcelain were used in these molds and then vibrated, dried and fired. After the porcelain specimens had been prepared, the specimens were grinded with a diamond bur. Finally the specimens were over glazed (Ivoclar Vivadent AG, FL-9494 Schaan, Liechtenstein) and stored in distilled water at until use.

The specimens were divided into five groups randomly and numbered each specimen. Then, surface roughnesses of specimens were recorded by profilometer (Surtronic 25; Taylor Hobson, Leicester, UK) for control (Table 1). Afterwards, the porcelain specimens were immersed in five different acidic agents for 168 hours to

Table 1. Mean Ra value for porcelains before treatments (control, $\mathrm{N}=6$ ).

\begin{tabular}{|c|c|c|c|}
\hline Porcelain & Acidic agent & Mean & Std. deviation \\
\hline \multirow{6}{*}{ Noritake } & Lemonade & 0.88 & 0.47 \\
\hline & Mineral water & 1.13 & 0.65 \\
\hline & Orange juice & 0.96 & 0.40 \\
\hline & Black-carriot juice & 1.06 & 0.32 \\
\hline & Coke & 3.03 & 2.50 \\
\hline & Total & 2.66 & 1.99 \\
\hline \multirow{6}{*}{ Ceramco 3} & Lemonade & 0.72 & 0.30 \\
\hline & Mineral water & 1.26 & 0.37 \\
\hline & Orange juice & 1.16 & 0.51 \\
\hline & Black-carriot juice & 1.16 & 0.52 \\
\hline & Coke & 0.86 & 0.56 \\
\hline & Total & 1.04 & 0.48 \\
\hline \multirow{6}{*}{ Total } & Lemonade & 0.81 & 0.40 \\
\hline & Mineral water & 1.20 & 0.50 \\
\hline & Orange juice & 1.06 & 0.45 \\
\hline & Black-carriot juice & 1.11 & 0.42 \\
\hline & Coke & 1.16 & 0.78 \\
\hline & Total & 1.07 & 0.53 \\
\hline
\end{tabular}


test the effect of acidic agents in first week. The acidic agents were chosen to most used drinks in Turkey: Coke (Coca Cola, The Coca Cola Company, New York, USA), orange juice (Icim orange juice, Ulker, Sakarya, Turkey), lemonade (Camlica, Ulker, Usküdar, Turkey), black-carrot juice (Doganay, Adana, Turkey) and mineral water (Kizilcahamam, Ankara, Turkey) (Figure 1) (Table 2). The pH values of acidic agents were measured with $\mathrm{pH}$ meter at the laboratory of Atatürk University Faculty of Medicine, Department of Biochemistry, Erzurum, Turkey (Figure 2). Then, the all specimens were rinsed with distilled water and dried. The specimens were evaluated surface roughness with profilometer (Figure 3). The statistically analysis of obtained data was performed with use two-way analysis of variance test.

Table 2. The $\mathrm{pH}$ value of acidic agents.

\begin{tabular}{|c|c|c|}
\hline Acidic agents & Ingredients & pH value \\
\hline $\begin{array}{c}\text { Coke (Coca Cola, The Coca Cola Company, } \\
\text { New York, USA) }\end{array}$ & $\begin{array}{l}\text { Carnonated water, high fructose corn syrup, caramel } \\
\text { color, phosphoric acid, natural flavors, caffeine }\end{array}$ & 3.63 \\
\hline Orange juice (Icim orange juice, Ulker, Sakarya, Turkey) & $\begin{array}{l}\text { Water, orange juice concentrate, fructose-glucose syrup, } \\
\text { sugar, antioxidant (ascorbic acid) }\end{array}$ & 4.53 \\
\hline Lemonade (Camlica, Ulker, Usküdar, Turkey) & $\begin{array}{l}\text { Water, lemon juice concentrate sugar, fructose-glucose } \\
\text { syrup, antioxidant (ascorbic acid), citric acid, }\end{array}$ & 4.07 \\
\hline Black-carriot juice (Doganay, Adana, Turkey) & $\begin{array}{l}\text { Water, black carriot, salt, boiled and pounded wheat, } \\
\text { turnip, chili papper, preservative (sodium benzoate) }\end{array}$ & 3.89 \\
\hline Mineral water (Kizilcahamam, Ankara, Turkey) & Different cations and anions & 5.88 \\
\hline
\end{tabular}

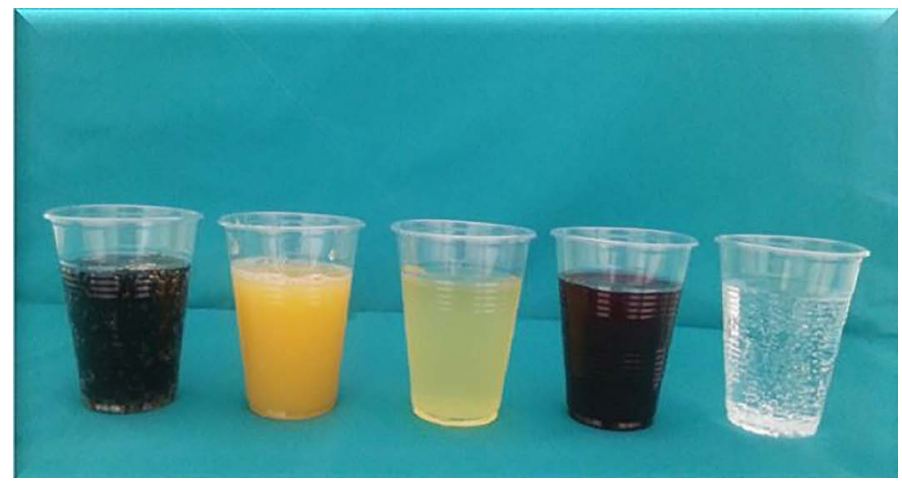

Figure 1. Acidic agents.

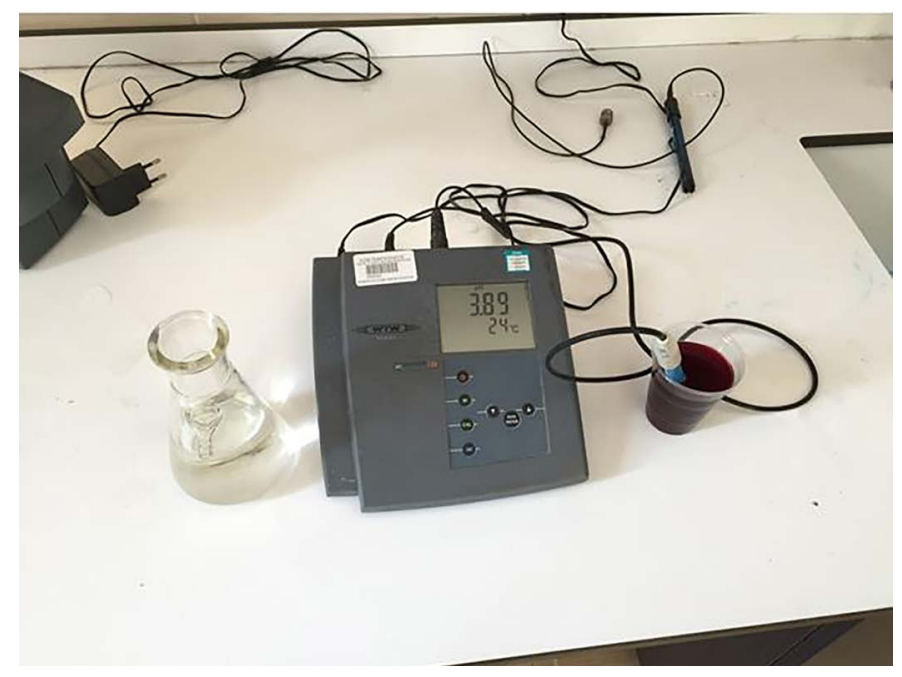

Figure 2. pH value measuring of acidic agents. 


\section{Results}

The results of two-way analysis of variance test showed that there were not statistically significant differences between acidic agents on surface roughness of feldspathic porcelain $(p>0.05)$.

There were statistically significant differences between acidic agents $(p<0.05)$ (Table 3$)$. The results showed that the highest surface roughness of value $(4.46 \pm 2.9 \mu \mathrm{m})$ was identified in lemonade at Noritake porcelain, the lowest surface roughness of value $(1.06 \pm 0.56 \mu \mathrm{m})$ was identified in mineral water at Ceramco 3 porcelain (Table 4).

\section{Discussion}

The hypothesis set as the premise of this study was not accepted, since the acidic agents were not affect surface roughness of feldspathic porcelain, but the other hypothesis was accepted, the type of acidic agents were affected surface roughness. The limitation of this study was that the acidic agents can rough the surface but it wasn't statistically significant, and increasing of roughness was not proportional to the acidic character of agents.

Dental ceramic technology is one of the fastest growing areas of dental material research and development due to its ability to closely match natural tooth color, biocompatibility, high resistance to wear and chemical inertness [7]. It was commonly used in the construction of fixed prosthesis dental porcelain should have full contours and polished surfaces before the cemented to patients. Otherwise, the rough porcelain surface is prone to adhesion and retention of oral microorganisms causing excessive plaque accumulation, gingival irritation, increased surface staining and poor esthetics of the restored teeth and thereby increasing the risk of dental caries and periodontal disease [8]-[10]. The oral cavity is a complex, aqueous environment where the restorative material is in contact with saliva [11] [12]. In addition, other factors such as low pH due to acidic foods and drinks

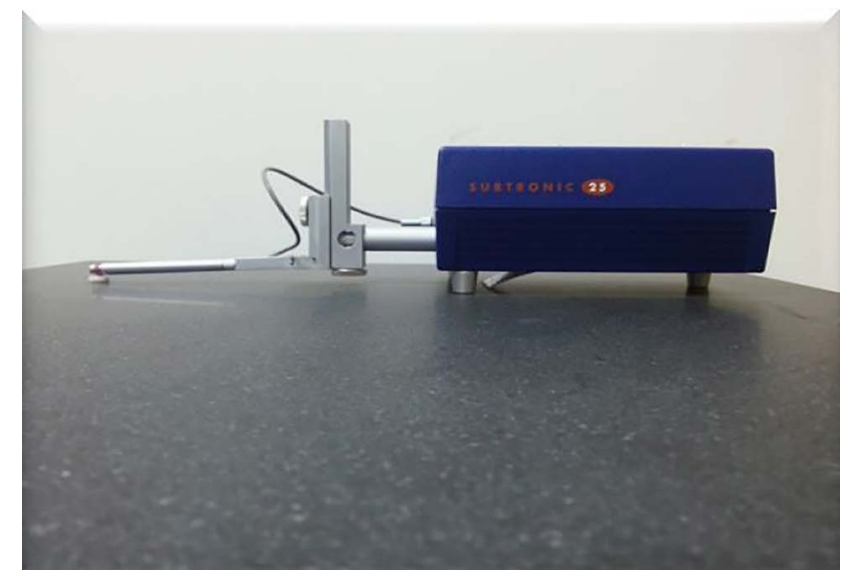

Figure 3. Testing of surface roughness with profilometer.

Table 3. The two-way analysis variance (ANOVA) test.

\begin{tabular}{|c|c|c|c|c|c|}
\hline Source & Type III Sum of Squares & Df & Mean Square & $\mathrm{F}$ & Sig. \\
\hline Corrected Model & $1.432^{\mathrm{a}}$ & 9 & 0.159 & 2.452 & 0.021 \\
\hline Intercept & 5.036 & 1 & 5.036 & 77.625 & 0.000 \\
\hline Porcelain & 0.108 & 1 & 0.108 & 1.668 & 0.202 \\
\hline Acidic Agents & 0.718 & 4 & 0.179 & 2.765 & 0.037 \\
\hline Porcelain*Acidic Agents & 0.606 & 4 & 0.151 & 2.335 & 0.068 \\
\hline Error & 3.244 & 50 & 0.065 & & \\
\hline Total & 9.711 & 60 & & & \\
\hline Corrected Total & 4.675 & 59 & & & \\
\hline
\end{tabular}


Table 4. Mean Ra value of acidic agents for porcelains $(\mathrm{N}=6)$.

\begin{tabular}{cccc}
\hline Porcelain & Mean & Std. deviation \\
\hline Lemonade & 4.46 & 2.90 \\
Mineral water & 2.53 & 0.96 \\
Orange juice & 1.76 & 0.68 \\
Noritake & 1.53 & 0.65 \\
Black-carrot juice & 3.03 & 2.50 \\
Coke & 2.66 & 1.99 \\
Tetal & 2.60 & 2.20 \\
Lemonade & 1.06 & 0.56 \\
Mineral water & 1.80 & 0.59 \\
Orange juice & 2.18 & 1.78 \\
Black-carrot juice & 3.23 & 1.59 \\
Coke & 2.17 & 1.58 \\
Total & 3.53 & 2.64 \\
Lemonade & 1.80 & 1.07 \\
Mineral water & 1.78 & 0.61 \\
Orange juice & 1.85 & 1.32 \\
Black-carrot juice & 3.13 & 2.00 \\
Coke & 2.42 & 1.80 \\
Total & &
\end{tabular}

may influence the material's mechanical and physical characteristics [13].

The availability and long-term success of prosthesis, depends upon the protection of the polished surface. The degradation of surface finish will cause the formation of surface cracks and after a while, leaving the porcelain metal sub-structure. In addition, surface deterioration will facilitate the involvement of plaque and microorganisms.

In the study, these drinks were selected because they are the favorite acidic drinks in our country. This is not too much work done on the subject in the literature. However Johansson et al. [14], in a study with coke's effect on dental erosion, compared potentially erosive habits between Saudi men with high and low indices of dental erosion. They reported that men with erosion consumed twice as much cola-type beverages, held beverages in their mouths $70 \%$ longer and were more likely to be mouth breathers than men without erosion [14].

Unknown by a large segment of society, dental erosion is resulting in a significant loss of tooth surfaces; acidic foods and beverages such as fruit juice, energy drinks and cola drinks potential relationship is reported in many studies [15].

After the lid is opened, coca cola and fruit juices lost gas and not changed the $\mathrm{pH}$ value which was reported in the studies [16] [17]. So, we stored the acidic agents in the covered cases and not changed the solutions.

\section{Conclusion}

With regard to the results, it was determined that acidic drinks statically were not affected to the surface roughness of feldspathic porcelain, but some acidic drinks had more surface roughening,

\section{Acknowledgements}

Presented as a poster at $38^{\text {th }}$ Annual Conference of the European Prosthodontic Association $\& 21^{\text {st }}$ Scientific Congress of the Turkish Prosthodontic and Implantology Association (EPA 2014) in Istanbul, Turkey, September 2014. 


\section{References}

[1] Raptis, N.V., Michalakis, K.X. and Hirayama, H. (2006) Optical Behavior of Current Ceramic Systems. The International Journal of Periodontics \& Restorative Dentistry, 26, 31-41.

[2] McLean, J.W. (1984) Perspectives on Dental Ceramics. In: Dental Ceramics. Proceedings of the 1st International Symposium on Dental Ceramics, Quintessence Publishing Co., Chicago.

[3] Morrow, R.M., Brown, C.E., Larkin, J.D., et al. (1973) Evaluation of Methods for Polishing Porcelain Denture Teeth. The Journal of Prosthetic Dentistry, 30, 222-226. http://dx.doi.org/10.1016/0022-3913(73)90059-0

[4] Kukiattrakoon, B., Hengtrakool, C. and Kedjarune-Leggat, U. (2010) The Effect of Acidic Agents on Surface Ion Leaching and Surface Characteristics of Dental Porcelains. The Journal of Prosthetic Dentistry, 103, 148-162. http://dx.doi.org/10.1016/S0022-3913(10)60021-2

[5] Kelly, J., Nishimura, I. and Campbell, S. (1996) Ceramics in Dentistry: Historical Roots and Current Perspectives. Journal of Prosthetic Dentistry, 75, 18-32. http://dx.doi.org/10.1016/S0022-3913(96)90413-8

[6] Milleding, P., Haraldsson, C. and Karlsson, S. (2002) Ion Leaching from Dental Ceramics during Static in Vitro Corrosion Testing. Journal of Biomedical Materials Research, 61, 541-550. http://dx.doi.org/10.1002/jbm.10109

[7] Nawafleh, N., Mack, F. and Ochsner, A. (2015) Masticatory Loading and Oral Environment Simulation in Testing Lithium Disilicate Restorations: A Structured Review. Advanced Structured Materials, 71, 189-215.

[8] Barghi, N., King, C.J. and Draughn, R.A. (1975) A Study of Porcelain Surfaces as Utilized in Fixed Prosthodontics. The Journal of Prosthetic Dentistry, 34, 314-319. http://dx.doi.org/10.1016/0022-3913(75)90109-2

[9] Barghi, N., Alexander, L. and Draugh, R.A. (1976) When to Glaze-An Electron Microscope Study. The Journal of Prosthetic Dentistry, 35, 648-653. http://dx.doi.org/10.1016/0022-3913(76)90322-X

[10] Clayton, J.A. and Green, E. (1970) Roughness of Pontic Materials and Dental Plaque. The Journal of Prosthetic Dentistry, 23, 407-411. http://dx.doi.org/10.1016/0022-3913(70)90007-7

[11] Hengtrakool, C., Kukiattrakoon, B. and Kedjarune-Leggat, U. (2011) Effect of Naturally Acidic Agents on Microhardness and Surface Micromorphology of Restorative Materials. European Journal of Dentistry, 5, 89-100.

[12] Okada, K., Tosaki, S., Hirota, K., et al. (2001) Surface Hardness Change of Restorative Filling Materials Stored in Saliva. Dental Materials: Official Publication of the Academy of Dental Materials, 17, 34-39. http://dx.doi.org/10.1016/S0109-5641(00)00053-1

[13] Honorio, H.M., Rios, D., Francisconi, L.F., et al. (2008) Effect of Prolonged Erosive pH Cycling on Different Restorative Materials. Journal of Oral Rehabilitation, 35, 947-953. http://dx.doi.org/10.1111/j.1365-2842.2008.01856.x

[14] Johansson, A.K., Lingstrom, P. and Birkhed, D. (2002) Comparison of Factors Potentially Related to the Occurrence of Dental Erosion in High- and Low-Erosion Groups. European Journal of Oral Sciences, 110, 204-211. http://dx.doi.org/10.1034/j.1600-0447.2002.11211.x

[15] Grippo, J.O., Simring, M. and Schreiner, S. (2004) Attrition, Abrasion, Corrosion and Abfraction Revisited: A New Perspective on Tooth Surface Lesions. Journal of the American Dental Association, 135, 1109-1118; Quiz 1163-1105.

[16] Çoğulu, D., Ersin, N. and Topaloğlu, A. (2008) Asitli içeceklerin üç farklı restoratif materyalin yüzey sertliği üzerine etkisinin incelenmesi. Diş Hekimliği Fakültesi Dergisi, 9, 7-12

[17] Aliping-McKenzie, M., Linden, R.W. and Nicholson, J.W. (2004) The Effect of Coca-Cola and Fruit Juices on the Surface Hardness of Glass-İonomers and “Compomers”. Journal of Oral Rehabilitation, 31, 1046-1052. http://dx.doi.org/10.1111/j.1365-2842.2004.01348.x 